\title{
MOTIVAÇÃO PARA APRENDER NO ENSINO MÉDIO: UMA ANÁLISE COM PROFESSORES E ALUNOS
}

\author{
Maria Luzia Silva Mariano ${ }^{1}$ \\ Katya Luciane de Oliveira² \\ Amanda Lays Monteiro Inácio 3
}

\begin{abstract}
RESUMO: O presente estudo objetivou identificar como os professores do Ensino Médio percebem a motivação para aprender de seus alunos e articular tais resultados com a qualidade motivacional apresentada pelos estudantes, tendo como base a Teoria da Autodeterminação. Participaram dez docentes de instituições públicas dos estados de Minas Gerais e do Paraná, que responderam a um questionário com oito questões sobre o construto da motivação e ainda 524 estudantes do Ensino Médio $(M=16,5 ; D P=1,49)$, ambos os sexos, avaliados por meio do Continuum de motivação para aprender. Os resultados indicaram que os professores perceberem seus alunos como motivados para ingressar no mercado de trabalho ou para dar continuidade aos estudos. Os estudantes se apresentaram mais orientados pela motivação extrínseca por regulação identificada. Os dados foram discutidos à luz da teoria, visando a identificação de suas implicações psicoeducacionais.
\end{abstract}

Palavras-chave: Docência. Motivação. Ensino Médio.

\section{MOTIVATION TO LEARN IN HIGH SCHOOL: AN ANALYSIS WITH TEACHERS AND STUDENTS}

ABSTRACT: The present study aimed to identify how the teachers of High School perceive the motivation to learn from their students and to articulate these results with the motivational quality presented by the students, based on the Theory of Self Determination. Ten professors from public institutions in the states of Minas Gerais and Paraná participated, who answered a questionnaire with eight questions about the motivation construct and 524 high school students ( $M=16.5$, $S D=1.49$ ), both the sexes, evaluated through the Continuum of motivation to learn. The results indicated that teachers perceive their students as motivated to enter the labor market or to continue their studies. The students were more oriented by the extrinsic motivation by the identified regulation. The data were discussed based on theory, aiming at the identification of its psychoeducational implications.

Keywords: Teaching. Motivation. High School.

\footnotetext{
${ }^{1}$ Mestre em Educação. Doutoranda em Educação da Universidade Estadual de Londrina (UEL) Londrina - PR/Brasil. E-mail: malumariano@yahoo.com.br

${ }^{2}$ Doutora em Psicologia, Desenvolvimento Humano e Educação. Professora da Universidade Estadual de Londrina (UEL). Londrina - PR/Brasil.E-mail: katyauel@gmail.com

${ }^{3}$ Mestre em Educação. Doutoranda em Psicologia na Universidade São Francisco. Campinas-SP/Brasil E-mail: amandalmonteiroo@gmail.com
} 


\section{MOTIVACIÓN PARA APRENDER EN LA ESCUELA SECUNDARIA: UN ANÁLISIS CON PROFESORES Y ESTUDIANTES}

RESUMEN: El presente estudio objetivó identificar cómo los profesores de la Enseñanza Media perciben la motivación para aprender de sus alumnos y articular tales resultados con la calidad motivacional presentada por los estudiantes, teniendo como base la Teoría de la Autodeterminación. Diez profesores de instituciones públicas de los Estados de Minas Gerais y Paraná, respondieron a un cuestionario con ocho preguntas sobre la construcción de la motivación y 524 estudiantes de secundaria ( $M=16,5 ; D P=1,49)$, ambos sexos, evaluados por medio de un continuum de la motivación para aprender. Los resultados indicaron que los profesores perciben a sus estudiantes como motivados para entrar en el mercado laboral o para continuar sus estudios. Los estudiantes estaban más orientados por la motivación extrínseca por la regulación identificada. Los datos fueron discutidos a la luz de la teoría, con el objetivo de identificar sus implicaciones psicoeducativas Palabras clave: Docencia. Motivación. Enseñanza Media.

A motivação é um construto multidimensional e complexo que envolve metas traçadas pelos indivíduos a fim de alcançar um determinado objetivo. A percepção da motivação pode ser feita por meio de ações ou da verbalização de um indivíduo motivado ou não a fazer alguma coisa. No âmbito escolar pode ser notada, por exemplo, por meio da aprendizagem bem-sucedida, do empenho ou do desempenho apresentado pelo aluno (BZUNECK, 2009; BZUNECK; BORUCHOVITCH, 2016; PANSERA et al., 2016).

Diversas teorias são empregadas para a compreensão da motivação humana, não sendo possível sintetizar conceitos e terminologias que a definam. Teorias como a da Autoeficácia, Metas de Realização ou a Teoria da Autodeterminação buscam entender e explicar a motivação apresentada pelos alunos para aprender (BZUNECK, 2009; BZUNECK; BORUCHOVITCH, 2016). Para o presente estudo adotou-se a Teoria da Autodeterminação como base teórica.

Inicialmente, a motivação intrínseca e a motivação extrínseca eram caracterizadas sob uma perspectiva de mera contraposição. No entanto, após vasta revisão literária feita por Edward L. Deci e Richard M. Ryan, na década de 1970, essas proposições passaram a ser classificadas como insuficientes e muito simplistas. Dessa feita, a relação de contraposição entre motivação intrínseca e extrínseca foi superada com a elaboração de um Continuum de motivação (BELUCE; OLIVEIRA, 2016; BZUNECK; BORUCHOVITCH, 2016; REEVE; DECI; RYAN, 
2004).

Esse Continuum se inicia na desmotivação, passa por quatro diferentes tipos de regulação externa qualitativa até chegar à regulação interna, que caracteriza a motivação intrínseca (REEVE et al., 2004). Assim, o Continuum de regulação do comportamento pode ser classificado em: desmotivação, regulação externa, regulação introjetada, regulação identificada, regulação integrada e motivação intrínseca (BELUCE; OLIVEIRA, 2016; DECl; RYAN, 1985; PERASSINOTO; BORUCHOVITCH; BZUNECK, 2013).

A desmotivação é caracterizada pela falta de intenção ou de motivação para a realização de uma determinada tarefa. $O$ indivíduo regulado de maneira externa age com o intuito de receber algum tipo de recompensa ou de evitar punições. Aquele regulado de maneira introjetada age por pressão interna, a fim de evitar algum sentimento de culpa ou ansiedade. A regulação identificada, por sua vez, caracteriza o indivíduo que percebe a importância de realizar determinada atividade para atingir o objetivo por ele estabelecido. Pessoas reguladas por uma orientação motivacional integrada conseguem perceber a importância da atividade, não sendo possível separar o que é externo e o que é interno ao indivíduo. Por fim, a motivação intrínseca é caracterizada por total autonomia e autodeterminação dos indivíduos, na qual estes realizam as tarefas por escolha e interesse próprios (BZUNECK et al., 2015; REEVE et al., 2004).

O aluno é denominado como intrinsecamente motivado quando ele mostra envolvimento com as atividades propostas, interesse nos conteúdos que estão sendo desenvolvidos, busca estratégias para vencer os desafios que aparecem, superando as suas capacidades e conhecimentos prévios e sentindo orgulho dos resultados alcançados. Em contrapartida, os alunos desmotivados são classificados como passivos face às atividades a serem realizadas, desinteressados quanto aos conteúdos apresentados, não demonstram empenho perante as dificuldades e não encontram prazer na realização das tarefas (MARIANO, 2015; PANSERA et al., 2016; RYAN; DECI, 2000).

De forma análoga, para que o aluno se sinta motivado, também é necessário que ele satisfaça três necessidades psicológicas básicas e que são inatas ao seu desenvolvimento, quais sejam, autonomia, competência e pertencimento (BELUCE; OLIVEIRA, 2016; DECI; RYAN, 
1985; PERASSINOTO et al., 2013). A necessidade de autonomia consiste no fato de o indivíduo realizar uma tarefa por vontade própria e não por determinação externa. Sendo assim, sob essa perspectiva, autonomia significa autogoverno e liberdade. A necessidade de competência está ligada à realização de determinada tarefa de forma positiva. Já a necessidade de pertencimento diz respeito ao fato de o indivíduo estabelecer laços com o ambiente em que está inserido de forma a se sentir parte dele.

A sala de aula é um importante campo de estudo no qual é possível aplicar as teorias motivacionais, devido a sua grande complexidade, heterogeneidade e até mesmo imprevisibilidade dos acontecimentos. De acordo com Bzuneck (2009), nas últimas décadas, principalmente a partir de 1970, os estudos sobre motivação aplicada ao contexto escolar têm aumentado consideravelmente (MAIESKI et al., 2017; OLIVEIRA; SANTOS; INÁCIO, 2017; SANTOS; MORAES; LIMA, 2018). O sistema educacional brasileiro passou por fortes mudanças com o decorrer do tempo no que tange à maneira como a educação passou a ser ofertada e também às legislações educacionais. Contudo, essas mudanças não foram suficientes para tratar dos diversos componentes que podem contribuir ou dificultar a aprendizagem dos estudantes, dentre eles, a motivação (KRAWCZYK, 2011).

É frequente por parte dos professores ou mesmo da equipe diretiva das escolas reclamações quanto ao comportamento dos estudantes em sala de aula ou a sua falta de vontade de fazer as atividades propostas, principalmente no Ensino Médio. Além disso, estudos indicam a diminuição da motivação intrínseca após os primeiros anos escolares, que caracterizam o Ensino Fundamental. Os alunos passam a pautar suas atitudes na obtenção de recompensas ou de resultados positivos, que evitem punições como castigo, tarefas extras ou mesmo uma reprovação durante o período letivo (PANSERA et al., 2016; RYAN; DECl, 2000; RUFINI; BZUNECK; OLIVEIRA, 2011).

Brophy (1999) afirma que a própria sala de aula não é um ambiente que contribui com a motivação intrínseca. Os alunos passam um tempo muito grande cumprindo prazos e executando tarefas que Ihes são impostas, sem que sejam consideradas as escolhas que eles mesmos desejam fazer. Aliado a isso, a avaliação do desempenho escolar é realizada, muitas vezes, por meio de atividades que valem nota e não consideram de forma abrangente se o 
aluno está ou não preparado e confiante para obter um bom desempenho e, ainda mais importante, se apreendeu efetivamente o conteúdo ministrado, o que corrobora com a diminuição da motivação intrínseca dos estudantes.

Outro elemento que pode influenciar na qualidade motivacional do aluno é o estilo motivacional do professor (COSTA et al., 2016; COUTINHO; CUCONATO; ALCANTARA, 2017; KAULFUSS; BORUCHOVITCH, 2016). Segundo Costa et al. (2016), existem docentes que adotam uma postura autoritária, sendo percebidos como controladores, e ainda aqueles que fazem uso de uma conduta que promove a autonomia dos estudantes. Guimarães (2004) esclarece que o estilo motivacional apresentado pelo professor varia de acordo com as suas habilidades adquiridas, de sua personalidade e também é influenciado pela quantidade de alunos em sala de aula, tempo lecionando, idade, gênero, concepção ideológica e até mesmo o tipo de relacionamento estabelecido com o corpo diretivo.

Professores promotores de autonomia estimulam o desenvolvimento e a satisfação das necessidades psicológicas básicas (autonomia, competência e pertencimento) de seus alunos. Eles proporcionam aos estudantes razões significativas para a realização de atividades que aparentemente não despertam o seu interesse e consideram o ritmo particular de aprendizagem e desenvolvimento de cada um. A linguagem também é utilizada de forma acessível e não controladora, além de apoiarem as decisões que são tomadas de forma madura e respeitarem as manifestações de emoções negativas em sala de aula (MACHADO et al., 2012).

Diante do exposto, o professor tem o dever de identificar as dificuldades ou até mesmo os pontos de insatisfação dos alunos durante as aulas e desenvolver novas estratégias motivacionais que proporcionem a satisfação na realização das tarefas. Em oposição, professores controladores desconsideram a visão do aluno ou até mesmo não permitem que estes se manifestem, o que além de não promover a autonomia, extrai a autenticidade, oferecendo incentivos externos para se atingir o padrão de comportamento idealizado. $O$ controle exercido pode ser direto ou indireto. No primeiro caso é feito por meio do estabelecimento de prazos ou controles verbais, situações em que os alunos percebem que o motivo para agir está fora da atividade. O segundo se dá por sentimentos de culpa, vergonha 
ou ansiedade projetados nos alunos, pois agir conforme o que é socialmente esperado evita constrangimentos e sensações desagradáveis (MACHADO et al., 2012).

A motivação extrínseca é altamente promovida pelo controle exercido de maneira direta por parte do professor, em que recompensas, ameaças e punições são apresentadas aos alunos. A atitude do professor tem por objetivo moldar a reação do aluno para o que ele considera como desejável para a sala de aula. O aluno percebe a sua competência somente quando recebe esse incentivo extrínseco, seja ele uma recompensa verbal ou mesmo material. Dessa forma, a realização da atividade tem o objetivo apenas de receber as recompensas propostas. Consequentemente, tal atitude proporciona a diminuição da motivação intrínseca dos estudantes (MACHADO et al., 2012; PANSERA et al., 2016; RYAN; $\mathrm{DECl}, 2000)$.

Outro fator importante e que influencia de forma decisiva na motivação que o aluno apresenta durante as aulas é o domínio e afinidade que ele tem com o conteúdo que está sendo ministrado. Linnenbrink e Pintrich (2002) discutem que os alunos precisam ter habilidades cognitivas e motivação para apresentarem um bom rendimento escolar, sendo essencial o interesse e o domínio por parte do aluno quanto ao conteúdo que está sendo desenvolvido pelo professor. A afinidade e o domínio quanto às disciplinas tornam-se mais evidentes no Ensino Médio, etapa em que as disciplinas são mais fragmentadas e em que se espera dos alunos maior conhecimento específico de cada conteúdo. Sendo assim, a motivação não é descrita pelos autores como um fator estável, pois ela varia de acordo com o ambiente e a situação em que o aluno se encontra.

Em face a essas conjecturas, tem-se que o processo de ensino possui em sua gênese a busca pelo conhecimento, que possibilitará ao indivíduo a percepção sobre a sua existência e também sobre o seu papel no desenvolvimento da sociedade (MOREIRA; OLIVEIRA; SCACCHETTI, 2016). Nesse processo, o professor exerce um papel fundamental, cabendo a ele, dentre outras funções, auxiliar no desenvolvimento da motivação, a fim de que os estudantes obtenham sucesso ao longo da educação formal e se sintam capazes de exercer a autonomia frente às escolhas futuras (COSTA et al., 2016; MAIESKI; OLIVEIRA; BZUNECK, 2013). 
É possível inferir que a qualidade do ensino que é ofertado está intimamente ligada à qualidade do profissional que a exerce. Cabe também ressaltar que a ação docente desses profissionais é influenciada por fatores internos e externos, ou seja, o professor também apresenta algum tipo de motivação para atuar na educação, seja ela uma convicção pessoal ou a necessidade de receber um salário. Essas questões afetam diretamente a qualidade do ensino ofertado e consequentemente a motivação dos próprios estudantes (MAIESKI et al., 2013). Em face ao que foi apresentado, o presente estudo objetivou identificar como os professores do Ensino Médio percebem a motivação para aprender de seus alunos e articular tais resultados com a qualidade motivacional apresentada pelos estudantes, tendo como base a Teoria da Autodeterminação

\section{Método}

\section{Participantes}

Participaram da pesquisa dez professores que atuam no Ensino Médio (todos oriundos de escolas públicas, estaduais, de porte médio e localizadas em regiões centrais dos estados de Minas Gerais e do Paraná). Desse total, $60 \%(n=6)$ pertenciam ao sexo feminino. A média de idade foi de 38 anos e 4 meses, tendo o mais novo 24 anos e o mais velho 58 anos; $40 \%$ $(n=4)$ lecionavam disciplinas na área de Ciências Biológicas, $50 \%(n=5)$ na área de Humanas e $10 \%(n=1)$ na área de Exatas. Do total, $70 \%(n=7)$ eram do estado de Minas Gerais e $30 \%(n=3)$ do Paraná.

Participaram também 524 estudantes, alunos dos professores respondentes do questionário sobre motivação. Deles, $57,8 \%(n=303)$ pertencia ao sexo feminino. A idade média dos estudantes foi de 16 anos e 5 meses ( $D P=1,49)$, sendo 14 anos a idade mínima e 27 a idade máxima. Do total, $70 \%$ ( $n=372)$ eram do estado de Minas Gerais e 30\% $(n=152)$ do Paraná.

\section{Instrumentos}

Tendo como base a Teoria da Autodeterminação (BZUNECK, 2009), foi elaborado pelas autoras um questionário contendo 8 questões dissertativas que abordavam o entendimento do professor sobre o que seria a motivação e aspectos relacionados ao contexto escolar. As 
perguntas consistiam em: 1) O que você entende por motivação? 2) Como você percebe a motivação para aprender dos seus alunos durante as suas aulas? 3) Os seus alunos apresentam motivação para ingressar no mercado de trabalho? 4) Você percebe o foco da motivação dos seus alunos voltado para a inserção no mercado de trabalho (realização de algum curso profissionalizante, ex.: Senai, Sesi) ou para dar continuidade aos estudos (cursar uma universidade)? 5) Você acredita que a motivação dos seus alunos varia de acordo com o foco por eles estabelecido? 6) No caso de o aluno não estar, em sua opinião, motivado aos estudos, a que você atribui essa falta de motivação? 7) Em sua opinião, os alunos estão preparados para a fazer uma escolha profissional ao sair do ensino médio? Justifique sua resposta e 8) "Você gostaria de acrescentar algo que não foi tratado neste questionário?".

$\mathrm{Na}$ amostra de estudantes foi aplicado o questionário de Continuum Motivacional de autoria de Rufini, Bzuneck e Oliveira (2011), que avalia a qualidade motivacional dos alunos para frequentar a escola. A escala consiste em 25 itens com opções de respostas em escala Likert de 5 pontos, que variam de nada verdadeiro até totalmente verdadeiro. Os alunos assinalaram qual o grau de intensidade na alternativa apresentada dizia a seu respeito. 0 instrumento foi validado por meio da análise fatorial exploratória realizada pelos autores.

\section{Procedimentos}

A pesquisa atendeu a todos os dispositivos da Resolução 246/2012 do Conselho Nacional de Saúde e seus complementares e foi aprovada pelo Comitê de Ética em Pesquisa da universidade a qual está vinculada. Após a aprovação, as coletas foram previamente agendadas e tiveram duração aproximada de 50 minutos, sendo realizadas de forma coletiva, em sala de aula, com os alunos e individualmente com os professores. Destaca-se que foram convidados a participar da pesquisa 52 professores atuantes nas escolas participantes, no entanto, somente 10 se dispuseram a responder ao questionário.

Os professores que consentiram assinaram ao Termo de Consentimento Livre e Esclarecido (TCLE) e responderam ao questionário, no momento da coleta, com os alunos ou no período destinado à realização da atividade pedagógica. Os alunos maiores de 18 anos assinaram o Termo de Consentimento Livre e Esclarecido e os menores de idade somente participaram após o consentimento dos responsáveis por meio da assinatura do TCLE. 


\section{Análise de Dados}

Visando atender os objetivos propostos, as respostas dos professores foram analisadas qualitativamente, individualmente e em conjunto, a fim de categorizar as respostas mais frequentemente relatadas. Além disso, os dados dos estudantes foram organizados em planilha eletrônica e submetidos à estatística descritiva realizada por meio do Programa IBM Statistical Package for the Social Sciences (SPSS), versão 22.0.

\section{Resultados e discussão}

A fim de conceber a percepção da motivação dos seus alunos, os professores foram convidados a responder 8 questões dissertativas acerca do tema. A primeira questão consistia em: "O que você entende por motivação?". Dos 10 professores que responderam ao questionário, 3 (30\%) definiram como motivação aquilo que dá sentido à ação do sujeito e o que o move em direção a algo. Outros 3 (30\%) definiram a questão como a capacidade de estimular/incentivar as pessoas. Os demais professores deram respostas distintas entre si, citando questões como se sentir capaz, interesse e entusiasmo para realizar uma atividade, algo inicial e constante ou resposta positiva a um trabalho bem desempenhado.

Quando perguntados a respeito do seu entendimento em relação à motivação, foi possível perceber que a maioria dos professores compreende o sentido da palavra, ao ponderarem que esta é o que move o sujeito em direção a algo. Foi possível perceber também que eles têm a percepção da sua responsabilidade enquanto promotores da motivação ao responderem que se refere à capacidade de incentivar as pessoas. As duas categorizações são pertinentes, visto que a motivação do professor e seu manejo em sala de aula influenciam substancialmente a motivação dos alunos (COSTA et al., 2016; KAULFUSS; BORUCHOVITCH, 2016).

Na segunda questão, os professores responderam a pergunta: “Como você percebe a motivação para aprender dos seus alunos durante as suas aulas?". 7 (70\%) responderam que percebem a motivação dos seus alunos quando eles demonstram interesse no conteúdo por meio da participação, dos questionamentos e das considerações que fazem no decorrer do desenvolvimento da matéria. Um professor (10\%) definiu a motivação dos seus alunos 
durante as aulas como algo inconstante. Outro professor (10\%) relatou que ultimamente está difícil motivar seus alunos, fato decorrente do uso de celulares e das redes sociais. Por fim, outro professor (10\%) considerou a importância de utilizar os conhecimentos por ele adquiridos para motivar seus alunos e proporcionar que eles saiam da posição de espectadores e passem a agir perante seus problemas de forma autônoma.

Com base nisso, é possível observar que a grande maioria dos professores considerou que a motivação é perceptível quando os alunos participam das aulas, perguntam, interagem e apresentam bons resultados nas atividades avaliativas. Essa visão corrobora com Pansera et al. (2016) e Ryan e Deci (2000) ao afirmarem que os alunos motivados intrinsecamente se envolvem nas tarefas propostas e apresentam melhor rendimento acadêmico. É fato que não foi solicitado ao professor que diferenciasse a motivação dos seus alunos em intrínseca ou extrínseca, no entanto, ressalta-se que os alunos motivados extrinsecamente também cumprem as tarefes propostas. Eles não o fazem pelo valor em sim da atividade, mas a fim de mostrar sua capacidade para alguém, para receber uma recompensa ou mesmo para evitar punições (BZUNECK et al., 2015; REEVE et al., 2004).

Na terceira questão, os professores responderam à seguinte pergunta: “Os seus alunos apresentam motivação para ingressar no mercado de trabalho?". 5 professores (50\%) consideraram a afirmativa como verdadeira. Apenas 1 deles (10\%) considerou que seus alunos não apresentavam tal motivação e os outros 4 professores (40\%) avaliaram que alguns alunos apresentavam motivação para ingressar no mercado de trabalho e outros não apresentavam.

De forma análoga, na quarta questão os professores responderam: "Você percebe o foco da motivação dos seus alunos voltado para a inserção no mercado de trabalho (realização de algum curso profissionalizante, por exemplo: Senai, Sesi) ou para dar continuidade aos estudos (cursar universidade)?". Os resultados indicaram que 4 professores (40\%) responderam que seus alunos apresentavam a motivação voltada para a inserção no mercado de trabalho ou para o ingresso em algum curso superior ao final do Ensino Médio. Outros 2 professores (20\%) responderam que os seus alunos ainda eram indecisos quanto ao caminho a seguir e que não apresentavam condições para realizar tal escolha. Os demais professores responderam que seus alunos não demonstravam tal interesse, pois eram oferecidas poucas 
oportunidades fora da instituição escolar e eles não teriam condições financeiras de dar continuidade a esse processo, ou responderam que alguns alunos se preocupavam, outros apresentavam uma necessidade imediatista para ingresso no mercado de trabalho ou ainda outros não tinham foco.

Ao analisar as questões 3 e 4, é perceptível que maioria dos professores afirmou que os seus alunos apresentam motivação para ingressar no mercado de trabalho ou para dar continuidade aos estudos. De acordo com o Instituto Brasileiro de Geografia e Estatística IBGE (2014), apenas 55\% dos jovens com idade entre 18 e 24 anos frequentavam o Ensino Superior no ano de 2013. O dado é ainda mais alarmante quando verificada a porcentagem de apenas 15,2\% de pessoas entre 25 e 34 anos com Ensino Superior completo. Esses dados evidenciam considerável nível de evasão escolar não só no Ensino Superior, mas também na etapa de transição que se inicia no Ensino Médio, já que a taxa de jovens de 15 a 17 anos que frequentava essa faixa escolar em 2013 era de 84,3\%.

O alto índice de evasão escolar é um dado preocupante e um assunto que precisa ser estudado com mais profundidade, a fim de que se possa identificar os fatores que contribuem para tal cenário. Segundo Krawczyk (2011), é inegável que as transformações curriculares pelas quais o Ensino Médio vem passando desde sua constituição enquanto parte do Ensino Básico não acompanham as mudanças que perpassam o cenário da adolescência, com políticas públicas efetivas para os menos favorecidos e que leve em consideração as especificidades das instituições escolares. Aliado a isso, a atenção que o professor dispensa ao aluno é fundamental para que ele consiga satisfazer as suas necessidades psicológicas básicas, como autonomia, competência e pertencimento, e, consequentemente, sentir-se motivado a aprender (MAIESKI et al., 2013).

Na quinta questão, os professores responderam à pergunta: "Você acredita que a motivação dos seus alunos varia de acordo com o foco por eles estabelecido?”. Dentre os 10 professores, 6 (60\%) responderam de forma afirmativa. Dois (20\%) indicaram que a motivação variava de acordo com o foco e com a realidade socioeconômica dos alunos. Um (10\%) respondeu que a motivação variava de acordo com o contexto em que os alunos viviam e o outro professor (10\%) respondeu que a motivação dos alunos variava de acordo com o foco 
por eles estabelecido e também de acordo com a pressão que a família exercia sobre eles.

De fato, todos os quesitos citados influenciam, não só na motivação apresentada pelos alunos, mas nas suas necessidades internas e também nos objetivos que eles vão traçar para o seu futuro. No entanto, há que se ponderar que a atual forma de organização do Ensino Médio não tem conseguido atingir os alunos de forma efetiva, a fim de lhes proporcionar uma formação crítica e consciente. A estruturação da educação não é atraente aos alunos, visto que eles chegam à escola com uma bagagem cultural muito ampla devido ao acesso às informações em demasia e não encontram o direcionamento dessas informações no contexto escolar, com aulas meramente expositivas e pouco interessantes (AZEVEDO; REIS, 2014; COUTINHO et al., 2017; INÁCIO, 2018).

O direito à aprendizagem e à formação cidadã, que são previstos na Lei de Diretrizes e Bases da Educação Nacional (LDBEN/96), não são garantidos na atual forma de oferta da educação, sobretudo no que concerne ao Ensino Médio (KRAWCZYK, 2011). A superlotação das salas de aula e a carga horária excessiva prejudicam o desenvolvimento dos conteúdos escolares e oferecem riscos à saúde e ao desempenho do profissional de docência em sala de aula. Esse fato pode trazer consequências à aprendizagem dos estudantes e consequentemente ao ingresso no ensino superior e no mercado de trabalho (DIEHL; MARIN, 2016).

Na sexta questão, os professores responderam à pergunta: "No caso de o aluno não estar, em sua opinião, motivado aos estudos, a que você atribui essa falta de motivação?". Do total, 3 (30\%) atribuíram a desmotivação à forma como o sistema educacional está organizado. Essa visão varia desde a divisão de saberes e conteúdos obrigatórios até as péssimas estruturas e condições físicas como salas superlotadas. Os outros 7 professores apresentaram respostas distintas, como condições financeiras, falta de interesse familiar e baixa autoestima, falta de percepção do aspecto transformador da educação, questões sociais e psicológicas. Um dos professores citou a inversão de valores, em que ele comparou o baixo ganho de um profissional formado com o alto ganho de um profissional que não apresentava a formação de nível superior. Outro professor atribui a desmotivação a fatores como a família, sociedade, consumismo e também o sistema educacional de modo geral. É interessante 
observar como, na visão desses professores, os seus alunos não são motivados para frequentar a escola. Tal visão corrobora com os apontamentos feitos por Ryan e Deci (2000), Pansera et al. (2016) e por Rufini et al. (2011) de que a motivação intrínseca dos alunos diminui consideravelmente ao longo dos anos escolares.

A sétima questão: "Em sua opinião, os alunos estão preparados para fazer uma escolha profissional ao sair do ensino médio? Justifique sua resposta" foi a que apresentou maior convergência nas respostas dos professores. 5 (50\%) não consideram os seus alunos aptos a fazerem uma escolha profissional ao final do Ensino Médio. Dentre as justificativas constam a falta de maturidade ou informações insuficientes para a realização dessa escolha; falta de orientação vocacional, carência de momentos reflexivos e palestras instrutivas acerca do mercado de trabalho e ainda o fato de ser um período muito conturbado emocional e socialmente para os jovens. 4 professores (40\%) consideraram que a maior parte dos alunos não estava preparada para escolher uma profissão no futuro. Os motivos elencados foram imaturidade, falta de interesse próprio em buscar conhecer as possibilidades e condições financeiras insuficientes. Apenas 1 professor (10\%) considerou que a maturidade apresentada pelos alunos podia ser algo relativo, pois independia da escola, podendo variar com afinidades em determinada área de conhecimento descobertas por meio das experiências pessoais.

Com as respostas supracitadas verifica-se que a maior parte dos professores evidencia a importância de o estudante obter algum tipo de auxílio no momento de sua escolha de carreira. No entanto, ao considerarmos a convergência nas respostas quanto ao despreparo dos jovens para sua escolha é possível indagar até que ponto as instituições de ensino e o próprio currículo do Ensino Médio estão voltados e adaptados para esse foco. A esse respeito, Barros, Noronha e Ambiel (2015) afirmam que a decisão profissional pode ser considerada complexa, pois influencia nos mais diversos aspectos da vida do indivíduo. Por esse motivo é um momento considerado tão importante, no qual, muitas vezes, o jovem carece de auxílio, como o da Orientação Profissional (OP). Sendo assim, mais do que informações dispostas no currículo, cabe considerar o que efetivamente vem sendo feito para auxiliar os estudantes nesse momento, como abertura a profissionais habilitados para executar orientação profissional na escola, orientação e cursos aos docentes sobre a temática e, por fim, o auxílio 
aos estudantes em si, por meio de palestras, debates e atividades informativas.

A última questão foi aberta, para que os professores pudessem acrescentar algo que julgassem pertinente ou que não foi abordado no questionário. Nesse sentido, 6 professores (60\%) responderam que não havia nada a acrescentar quanto ao questionário apresentado. Um professor (10\%) deixou a resposta em branco. Um professor (10\%) ponderou que a organização das disciplinas varia de uma escola para outra, no entanto, os professores responsáveis por aquelas com menor carga horária precisam adequar os conteúdos pertinentes, optando por aquilo que consideram mais importante. Um professor (10\%) destacou a necessidade de investigações acerca do Ensino Médio noturno e que devem ser buscadas novas perspectivas para a melhoria educacional e, por fim, o último respondente (10\%) considerou que se o Ensino Médio fosse mais atrativo aos alunos, os professores consequentemente seriam mais motivados, sendo necessárias mudanças na estrutura educacional como um todo para que isto aconteça de modo efetivo.

As respostas evidenciam que muitas transformações são necessárias para que o ensino se dê de forma eficiente. Essas mudanças se referem ao âmbito estrutural das instituições de ensino e perpassam a maneira como este é ofertado, de forma engessada e sistematizada e também pela formação dos profissionais que atuam na educação (AZEVEDO; REIS, 2014; KRAWCZYK, 2011). Assim, pode-se afirmar que todas as questões elencadas influenciam de maneira decisiva na qualidade motivacional apresentada pelos alunos, tornando-se um desafio a ser superado no contexto educacional.

No que se refere aos resultados da motivação dos estudantes do Ensino Médio, a análise descritiva levantou as pontuações nas seguintes subescalas: desmotivação, motivação extrínseca com regulação externa, motivação extrínseca com regulação introjetada, motivação extrínseca com regulação identificada e motivação intrínseca. A Tabela 1, apresentada na sequência, indica a média de pontos, o desvio padrão e a pontuação máxima e mínima possível para cada subescala do Questionário de Continuum Motivacional. 
Tabela 1 - Média de pontos, desvio padrão, pontuação máxima e mínima para cada subescala do Continuum de motivação

\begin{tabular}{lccccc}
\hline \multirow{2}{*}{ Subescalas } & \multirow{2}{*}{ M } & DP & \multicolumn{2}{c}{ Pontuação } \\
\cline { 5 - 6 } \cline { 4 - 5 } & & 4,44 & 5 & Mínima & Máxima \\
\hline Desmotivação & 9,17 & 4,43 & 5 & 25 \\
Regulação Externa & 10,46 & 5,05 & 5 & 25 \\
Regulação Introjetada & 10,94 & 5 & 25 \\
Regulação Identificada & 22,09 & 4,02 & 5 & 25 \\
Motivação Intrínseca & 17,91 & 5,06 & &
\end{tabular}

Fonte: Elaborado pelas autoras.

Ao analisar a Tabela 1 é possível observar que os alunos obtiveram maior média $(M=22,09)$ na pontuação para a subescala de motivação extrínseca por regulação identificada, de um total de 25 pontos possíveis. De acordo com Reeve et al. (2004) e Bzuneck et al. (2015), o aluno regulado de maneira identificada é convencido da importância da tarefa que está realizando para que seja possível atingir a meta por ele traçada. É importante ressaltar que a média para a motivação intrínseca foi de 17,9 pontos, dos 25 que poderiam ser atingidos, e a média para a desmotivação foi a mais baixa dentre as subescalas disponíveis $(M=9,17)$.

É possível admitir que esses alunos não se encontram desmotivados para aprender, no entanto apresentam diminuição da motivação intrínseca de acordo com o avanço da idade escolar, conforme já evidenciado por Perassinoto et al. (2013). Ryan e Deci (2000) afirmam que o excesso de fiscalização, cobrança excessiva de prazos ou resultados pode ocasionar a diminuição da motivação intrínseca ao longo do processo de aprendizagem. No Ensino Médio, essas características são muito presentes, sendo que os alunos são cobrados para que apresentem bom rendimento e sejam aprovados em avaliações como o Exame Nacional do Ensino Médio (ENEM) e/ou vestibulares para ingresso no Ensino Superior (INÁCIO, 2018).

Outro fator que influencia de maneira decisiva na qualidade motivacional apresentada pelo aluno, como já citado anteriormente, é o estilo adotado pelo professor (COSTA et al., 2016; KAULFUSS; BORUCHOVITCH, 2016). O professor promotor da autonomia permite que os seus alunos satisfaçam de forma mais eficaz as necessidades psicológicas básicas (autonomia, competência e pertencimento). Ainda assim, é fundamental que o professor dispense a atenção adequada ao estudante, a fim de promover a sua autonomia, o seu senso de competência e de pertencimento ao grupo. Dessa forma, foi possível inferir que a 
autorregulação no processo de aprendizagem influencia de forma eficaz a obtenção de resultados, como o ingresso no mercado de trabalho ou uma escolha profissional consciente, por exemplo (PERASSINOTO et al., 2013; MAIESKI et al., 2013).

No entanto, se o professor não estiver motivado, ele não conseguirá transmitir e proporcionar motivação aos seus alunos. Maieski et al. (2013) afirmam que os professores motivados e entusiasmados tendem a influenciar seus alunos da mesma maneira, e que o inverso também é verdadeiro. É importante salientar que dentre os fatores que podem estar relacionados à desmotivação do professor estão a jornada de trabalho em diferentes instituições com carga horária excessiva, o número de alunos em sala de aula, falta de apoio institucional, entre outros, reflexos principalmente da falta de investimentos na educação em um processo tardio e inacabado (COSTA et al., 2016; CUNHA, 2017; FERREIRA; SILVA, 2017; INÁCIO, 2018; MARIANO, 2015).

É importante ressaltar que a regulação integrada não aparece na Tabela 1 do Continuum de motivação, o que pode ter ocorrido em virtude deste nível de motivação, que apresenta demasiada autonomia, estar muito próximo da motivação intrínseca, que é caracterizada por total autonomia e autodeterminação. $O$ indivíduo motivado extrinsecamente por regulação integrada escolhe adotar certo tipo de comportamento por realmente perceber a importância naquilo que ele está fazendo, ou seja, ele incorpora de tal maneira este comportamento que não é possível separar o que é externo ou interno a ele (REEVE et al., 2004).

\section{Considerações finais}

O presente estudo teve por objetivo identificar como os professores do Ensino Médio percebem a motivação para aprender de seus alunos e articular tais resultados com a qualidade motivacional apresentada pelos estudantes. É importante destacar que os dados referentes à motivação dos alunos foram apresentados a fim de que fosse possível sua comparação com a percepção dos professores. Ficou claro que os professores não percebem seus alunos como desmotivados, assim como os dados obtidos a partir do Continuum motivacional indicaram que os estudantes se encontram motivados extrinsecamente por 
regulação identificada. Em face do exposto, acredita-se que o presente estudo atingiu os objetivos a que se propusera, identificando a motivação para aprender dos alunos do Ensino Médio na perspectiva de seus professores e articulando a percepção do professor acerca da motivação dos seus alunos e a qualidade motivacional apresentada por estes.

Retomando o que fora exposto, é incontestável o papel desempenhado pelo professor no processo motivacional de seus alunos, pois apesar de ser algo inerente ao indivíduo, pode ser desenvolvido e aprimorado no contexto educacional. Nesse sentido, o professor deve optar por métodos de ensino que possibilitem a autonomia dos estudantes na resolução de problemas e tomada de decisão (COSTA et al., 2016; MAIESKI et al, 2013).

Outra questão a ser destacada é a forma como o Ensino Médio está organizado e ofertado atualmente. O sistema há muito tempo dá indícios de que não consegue abarcar as necessidades dos estudantes pertencentes a essa etapa de ensino. Diante disso, os currículos e as políticas educacionais de modo geral devem ser repensados, para que os jovens estudantes concluam seus estudos e tenham a possibilidade de se desenvolver nos mais diversos âmbitos, com competência para ingressar no ensino superior e, futuramente, no mercado de trabalho (AZEVEDO; REIS, 2014; CUNHA, 2017; FERREIRA; SILVA, 2017; KRAWCZYK, 2011). Essas mudanças devem visar também o bem-estar do professor, visto que as dificuldades enfrentadas durante a jornada de trabalho podem afetar a saúde do profissional de docência (DIEHL; MARIN, 2016).

Como limitação destaca-se a necessidade de que a amostra seja ampliada, sobretudo em relação aos professores, a fim de verificar de forma mais precisa os dados encontrados. No entanto, mesmo com tal limitação, as contribuições do estudo são demasiadamente relevantes, posto que poucos estudos integram a perspectiva do professor, principalmente no Ensino Médio, etapa que enfrenta importantes dificuldades na educação básica brasileira. Sugere-se ainda como agenda futura que seja investigada a motivação do professor em seu contexto de trabalho e ainda outras variáveis psicoeducacionais, tais como o emprego de estratégias de aprendizagem e dos estilos intelectuais. 


\section{Referências}

AZEVEDO, J. C.; REIS, J. T. (org.). O Ensino Médio e os desafios da experiência: movimentos da prática. São Paulo: Moderna, 2014.

BARROS, M. V. C.; NORONHA, A. N. P.; AMBIEL, R. A. M. Afetos, interesses profissionais e personalidade em alunos do ensino médio. Revista Brasileira de Orientação Profissional. v. 16, n. 2, p. 161-171, dez. 2015. Disponível em:

http://pepsic.bvsalud.org/scielo.php?script=sci_arttext\&pid=S1679-

33902015000200007\&lng=pt\&nrm=iso. Acesso em: 15 jan. 2019.

BELUCE, A. C.; OLIVEIRA, K. L. Escala de estratégia e motivação para aprendizagem em ambientes virtuais. Revista Brasileira de Educação, v. 21, n. 66, p. 593-610, jul./set. 2016. Disponível em: http://www.scielo.br/pdf/rbedu/v21n66/1413-2478-rbedu-21-66-0593.pdf. Acesso em: 14 jan. 2019.

BRASIL. Lei no 9.394, de 20 de dezembro de 1996. Estabelece as Diretrizes e Bases da Educação Nacional. (1996, 20 de dezembro). Brasília, DF: Presidência da República: Casa Civil. Disponível em: https://www.planalto.gov.br/ccivil_03/Leis/L9394.htm. Acesso em: 14 jan. 2019.

BROPHY, J. Motivating students to learn. Boston: McGraw Hill, 1999.

BZUNECK, J. A. A motivação do aluno: aspectos introdutórios. In: BORUCHOVITH, E.; BZUNECK, J. A. (org.). A Motivação do Aluno: Contribuições da Psicologia Contemporânea. Petrópolis: Vozes, 2009. p. 9-36.

BZUNECK, J. L.; BORUCHOVITCH, E. Motivação e Autorregulação da Motivação no Contexto Educativo. Psicologia Ensino \& Formação, v. 7, n. 2, p. 73-84, 2016. Disponível em:

http://dx.doi.org/10.21826/2179-58002016727584. Acesso em: 14 jan. 2019.

BZUNECK, J. A; OLIVEIRA, M. F. C; RUFINI, S. E.; OLIVEIRA, K. L. Estrutura fatorial de uma Escala de Motivação de Adolescentes para Leitura. Avaliação Psicológica, v. 14, n. 3, p. 375-383, dez. 2015. Disponível em: http://pepsic.bvsalud.org/scielo.php?script=sci_arttext\&pid=S167704712015000300010\&lng=pt\&nrm=iso. Acesso em: 14 jan. 2019.

COSTA, L. C. A.; PASSOS, P. C. B.; BELEM, I. C.; CONTREIRA, A. R.; VIEIRA, L. F. Estilo motivacional e comportamento assertivo de professores de Educação Física ao longo da carreira. Revista Brasileira de Educação Física e Esporte, v. 30, n. 2, p. 457-465, jun. 2016. Disponível em: http://dx.doi.org/10.1590/1807-55092016000200457. Acesso em: 14 jan. 2019.

COUTINHO, J. Z. S. F.; CUCONATO, L. C. S.; ALCANTARA, E. F. S. Motivação e aprendizagem no contexto escolar. Rev. Episteme Transversalis. v. 8, n. 2, p. 133-144, jul./dez. 2017. Disponível em: http://revista.ugb.edu.br/index.php/episteme. Acesso em: 14 jan. 2019.

CUNHA, L. A. Ensino Médio: Atalho para o passado. Educação \& Sociedade, v. 38, n. 139, p. $373-$ 384, abr./jun. 2017. Disponível em: http://dx.doi.org/10.1590/es0101-73302017176604. Acesso em: 14 jan. 2019.

DECI, E. L.; RYAN, R. M. Intrinsic Motivation and Self-Determination in Human Behavior. New York: Plenum Press, 1985.

DIEHL, L.; MARIN, A. H. Adoecimento mental em professores brasileiros: revisão sistemática da 
literatura. Estudos Interdisciplinares em Psicologia, v. 7, n. 2, p. 64-85, dez. 2016. Disponível em: http://pepsic.bvsalud.org/scielo.php?script=sci_arttext\&pid=S2236-64072016000200005. Acesso em: 14 jan. 2019.

FERREIRA, E. B; SILVA, M. R. Centralidade do ensino médio no contexto da nova "Ordem e Progresso". Educação \& Sociedade, v. 38, n. 139, p. 287-292, jun. 2017. Disponível em: http://dx.doi.org/10.1590/es0101-73302017179021. Acesso em: 14 jan. 2019.

GUIMARÃES, S. E. R. Motivação intrínseca, extrínseca e o uso de recompensas em sala de aula. In: BORUCHOVITCH; E.; BZUNECK, J. A. (org.). A motivação do aluno: contribuições da psicologia contemporânea. Petrópolis: Vozes, 2004. p. 37-57.

INÁCIO, A. L. M. Estilos Intelectuais, Estratégias de Aprendizagem, Compreensão de Leitura e Desempenho escolar no ensino médio. 2018. Dissertação (Mestrado) - Programa de PósGraduação em Educação, Universidade Estadual de Londrina, Londrina, 2018.

INSTITUTO BRASILEIRO DE GEOGRAFIA E ESTATÍSTICA (IBGE). Síntese de indicadores sociais: uma análise das condições de vida da população brasileira, 2014. Rio de Janeiro. Disponível em: http://biblioteca.ibge.gov.br/visualizacao/livros/liv91983.pdf. Acesso em: 14 jan. de 2019.

KAULFUSS, M. A.; BORUCHOVITCH, E. Atribuições causais de professores para o sucesso e o fracasso em ensinar. Psicologia Escolar e Educacional, v. 20, n. 2, p. 321-328, ago. 2016. DOI: http://dx.doi.org/10.1590/2175-353920150202974

KRAWCZYK, N. Reflexões sobre alguns desafios do ensino médio no Brasil hoje. Cadernos de Pesquisa, São Paulo, v. 41, n. 144, p. 752-769, set./dez., 2011. DOI:10.1590/S010015742011000300006

LINNENBRINK, E. A.; PINTRICH, P. R. Motivation as an enabler for academic success. School Psychology Review, v. 31, n. 3, p. 313-327, 2002. Disponível em:

http://psycnet.apa.org/record/2002-18945-003. Acesso em: 14 jan. 2019.

MACHADO, A. C. T. A.; RUFINI, S. E.; MACIEL, A. G.; BZUNECK. J. A. Estilos motivacionais de professores: preferência por controle ou por autonomia. Psicologia Ciência e Profissão, v. 32, n. 1, p. 188-201, out. 2012. DOI: http://dx.doi.org/10.1590/S1414-98932012000100014

MAIESKI, S.; OLIVEIRA, K. L.; BZUNECK, J. A. Motivação para aprender: o autorrelato de professores brasileiros e chilenos. Psico-USF, v. 18, n. 1, p. 53-64, abr. 2013. DOI: http://dx.doi.org/10.1590/S1413-82712013000100007

MAIESKI, S.; OLIVEIRA, K. L.; BELUCE, A. C.; RUFINI, S. E. Motivação de alunos do ensino fundamental: estudo de duas realidades culturais. Psicologia Escolar e Educacional, v. 21, n. 3, p. 601-608, dez. 2017. DOI: http://dx.doi.org/10.1590/2175-353920170213111129

\section{MARIANO, M. L. S. Qualidade Motivacional no Ensino Médio: Estudo sobre relações com a} maturidade e a escolha profissional. 2015. Dissertação (Mestrado em Educação) - Programa de Pós-Graduação em Educação, Universidade Estadual de Londrina, Londrina, 2015.

MOREIRA, A. E. C.; OLIVEIRA, K. L.; SCACCHETTI, F. A. P. O processo de ensino e aprendizagem em questão: implicações metodológicas e motivacionais. Educação Unisinos, v. 20, n. 1, p. 106116, jan./abr. 2016. Disponível em: Disponível em: http://revistas.unisinos.br/index.php/educacao/article/view/edu.2016.201.11. Acesso em: 20 
maio 2019.

OLIVEIRA, K. L.; SANTOS, A. A. A.; INÁCIO, A. L. M. Estratégias de aprendizagem no ensino médio brasileiro: análise exploratória dos resultados. Revista de Estudios e investigación en psicología y educación, v. Extr., n. 1, p. 337-341, dez. 2017. DOI:

https://doi.org/10.17979/reipe.2017.0.01.3041

PANSERA, S. M.; VALENTINI, N. C.; SOUZA, M. S.; BERLEZE, A. Motivação intrínseca e extrínseca: diferenças no sexo e na idade. Psicologia Escolar e Educacional, v. 20, n. 2, p. 313-320, mai./ago. 2016. DOI: http://dx.doi.org/10.1590/2175-353920150202972

PERASSINOTO, M. G. M.; BORUCHOVITCH, E.; BZUNECK, J. A. Estratégias de aprendizagem e motivação para aprender de alunos do Ensino Fundamental. Avaliação Psicológica, v. 12, n. 3, p. 351-359, dez. 2013. Disponível em:

http://pepsic.bvsalud.org/scielo.php?script=sci_arttext\&pid=S1677-

04712013000300010\&lng=pt\&nrm=iso. Acesso em: 14 jan. 2019.

REEVE, J.; DECI, E. L.; RYAN, R. M. Self-Determination Theory: A dialectical framework for understand sociocultural influences on student motivation. In: MCINERNEY, D. M.; VAN ETTEN, S. (org.). Big Theories Revisited. Connecticut: Age Publishing, 2004. p. 33-60.

RUFINI, S. E.; BZUNECK, J. A.; OLIVEIRA, K. L. Estudo de validação de uma medida de avaliação da motivação para alunos do ensino fundamental. Psico-USF, v. 16, n. 1, p. 1-9, jan. 2011. DOI: http://dx.doi.org/10.1590/S1413-82712011000100002

RYAN, R. M.; DECl, E. L. Self-determination theory and the facilitation of intrinsic motivation, social development, and wellbeing. American Psychologist, v. 55, n.1, p. 68-78, jan. 2000.

Disponível em: https://selfdeterminationtheory.org/SDT/documents/2000_RyanDeci_SDT.pdf. Acesso em: 14 jan. 2019.

SANTOS, A. A. A.; MORAES, M. S.; LIMA, T. H. Compreensão de leitura e motivação para aprendizagem de alunos do ensino fundamental. Psicologia Escolar e Educacional, v. 22, n. 1, p. 93-101, abr. 2018. DOI: http://dx.doi.org/10.1590/2175-35392018012208.

Recebido em: 26/10/2018

Aprovado em: 15/02/2019 